WellBeing International

WBI Studies Repository

$1-1975$

\title{
The Communication of Play Intention: Are Play Signals
}

Functional?

\author{
Marc Bekoff \\ University of Colorado
}

Follow this and additional works at: https://www.wellbeingintlstudiesrepository.org/acwp_asie

Part of the Animal Studies Commons, Comparative Psychology Commons, and the Other Animal Sciences Commons

\section{Recommended Citation}

Bekoff, M. (1975). The communication of play intention: Are play signals functional?. Semiotica, 15(3), 231-240.

This material is brought to you for free and open access by WellBeing International. It has been accepted for inclusion by an authorized administrator of the WBI Studies Repository. For more information, please contact wbisr-info@wellbeingintl.org.

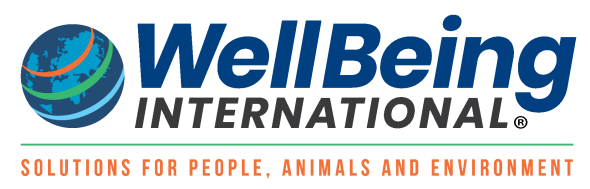




\title{
The Communication of Play Intention: Are Play Signals Functional?*
}

\author{
Marc Bekoff \\ University of Colorado
}

\section{INTRODUCTION}

It is a well established fact that animals, particularly mammals, engage in an activity called social play. ${ }^{1}$ Basic to any discussion of play is a consideration of the ways in which animals communicate play intention to one another. This process has been termed "metacommunication" by Bateson (1955). ${ }^{2}$ Although there have been many studies on a wide variety of mammals reporting the existence of 'play signals', $^{3}$ as late as 1967, Altmann (pp. 356-57) pointed out that " ... there has been no formal theory of the basic nature of metacommunication in sufficient operational terms ... to know just when you had an example of it." Nonetheless, Altmann (1962:279) had written earlier that "Primates include in their repertoire a set of social messages that serve to affect the way in which other social messages are interpreted. In a sense, the use of such messages involves communication about communication. It is therefore designated as 'metacommunication' ... " And, in his 1967 paper, Altmann concluded that metacommunication is basically different from other forms of communication. In Hinde's (1972) edited volume dealing with nonverbal communication, metacommunication is indexed as 'reflectiveness', or ability to communicate about the system itself. Thorpe (1972) finds no examples of metacommunication anywhere in the animal kingdom except in human speech. McBride (1968) implicates metacommunication in the evolution of human language, and Scheflen (1974) finds that metacommunicative behaviors are of great import in both verbal and nonverbal human interactions.

Indeed, these diverse views concerning metacommunication are understandable, due to the lack of rigorous, systematic analysis on the phylogeny, ontogeny, and demonstrable function(s) of what have been called 'play signals'. As concerns the functions of play signals in the initiation of social play, the most common finding is a temporal correlation between the occurrence of a particular behavior(s) and social play. ${ }^{4}$ Inferences about the supposed function of specific facial expressions, vocalizations, postures, odors, and gestures in the communication of play intent are drawn based on observed stimulus-response contingencies (see Carpenter, 1974:477-78). Thus far, with the exception of the example provided below, there have been no demonstrations that play signals function in a metacommunicative fashion.

\section{A DEFINITION OF METACOMMUNICATION}

For the purposes of this paper, and in keeping with earlier discussions of metacommunication (e.g., Altmann, 1962, 1967; Bekoff, 1972, 1976), metacommunication will have occurred when it can be shown that the performance of a particular behavior(s) has served to alter the significance of subsequent signal(s). An effective metacommunicative signal (hereafter called a 'play signal') should therefore alter the probability that a particular response will follow a given signal.

The importance of being able to communicate play intention becomes apparent when one analyzes the nature of the behaviors that are performed during social play. Typically, a playing animal uses actions that originate in other contexts, actions supposedly evolving earlier phylogenetically and for purposes other 
than play (Loizos, 1966). ${ }^{5}$ For example, during play, patterns of aggressive, reproductive, and predatory behavior are often observed. In order for one organism to communicate that 'the baring of my teeth that follows should not be interpreted as a sign of aggression', some mechanism for altering the significance of the bared teeth should exist. The qualification of the 'aggressive' signal may be accomplished through the use of play signals.

\section{HOW IS PLAY INITIATED AND MAINTAINED?}

As mentioned above, almost all behavior patterns observed during play originate in other contexts. Nonetheless, some actions, especially those used in the solicitation of play, appear to be specific to play. The play signals are generally clear and unambiguous, and often are performed in an 'exaggerated' manner (Bekoff, 1976). Play signals may occur either before or during a playful interaction. Little is known about the positioning of play signals within a play bout except for the casual observation that play bouts are usually preceded by a play signal or that play signals occur throughout the duration of a bout. Whether or not "...initiating signals are repeated whenever a clear restatement of purpose is necessary" (Simonds, 1974:198), in fact, remains to be studied. Figure 1 presents some possibilities for the appearance (positioning) of play signals either before and/or during an interaction. In infant canids (Bekoff, in preparation), play signals occur either before a play bout (a) or are dispersed randomly throughout (d). In bouts that were not preceded by an observable signal, play signals were not observed in increased frequency during the bout (e.g., the animals did not have to be more 'convincing' that 'this is play'). However, unsolicited bouts (bouts which do not begin with a play signal) tended to be shorter in length (i.e., in duration and number of actions performed) than bouts that had been preceded by a play signal. Furthermore, as bouts progressed, the frequency of play signals decreased sharply, and in bouts lasting a length of 36 actions (up to two minutes in duration), play signals were observed rarely after the 15th action.

In the play literature, it has been suggested that play intention can be communicated via various sensory modalities. That is, play may follow temporally the reception of some visual, auditory, or olfactory signal(s). Since we are visual animals, much of our research reflects this sensory bias. Accordingly, many workers have noted the occurrence of play signals such as the 'play face' (van Hooff, 1967; Fox, 1970; Chevalier-Skolnikoff, 1974), 'loose', bouncy gamboling approaches (Loizos, 1967; Sade, 1973; Bekoff, 1974), the 'play bow' (Tembrock, 1957; Bekoff, 1974), and the 'play pounce' (West, 1974).

Less work has been done to determine the importance of olfactory signals in the initiation and maintenance of play. In various rodents and seals (Wilson, 1973; Wilson and Kleiman, 1974), scent appears to be important during play. Wilson (1973), studying social development in the vole (Microtus agrestis), demonstrated that the difference in the amount of play observed in spnng- vs. autumn-born young could be traced to the fact that autumn born young do not produce a 'play scent'. By taking the scent back of the heads of spring-born voles and putting it on the back of the heads of autumn-born individuals, Wilson observed a large increase in the play activity of autumn-born young. In other rodents (Octodon degus, Octodontomys gliroides, and Pediolagus salinicola) and harbor seals (Phoca vitulina concolor), it has been found that olfactory exchange is enhanced during play (Wilson and Kleiman, 1974). While playing, the seals nose one another around the muzzle and nape of the neck, and an analysis of the amount of sebaceous material in the skin from different areas of the body showed that the muzzle and the nape of the neck contain more of this substance than other body areas. That olfactory signals function metacommunicatively has not been established. 
Figure 1. This figure shows some $(P)$ possibilities for the appearance of play signals $(P)$ either before or during play bouts. ( $\overline{\mathrm{P}}=$ NO observable play signal; $1,2,3$, and $4=$ various actions $)$.

a) This represents an interaction that has been solicited previously and during which no additional play signals are observed.

b) In this case, $\mathbf{P}$ occurs regularly after every 3 actions. There might also be a temporal factor, with $\mathbf{P}$ occurring every ' $n$ ' seconds.

c) $\mathbf{P}$ occurrs after a particular action (in this case, 1 ) is performed. It is possible also that $\mathbf{P}$ may regularly precede a particular action.

d) $P$ occurs randomly throughout a bout (after Bekoff, 1976).
a) $\mathbf{P} 2141323 \ldots$

b)

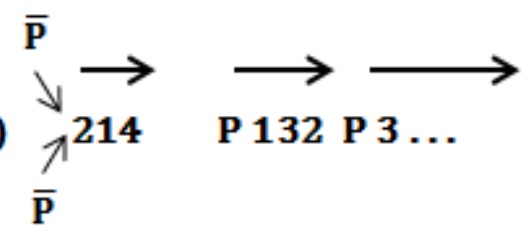

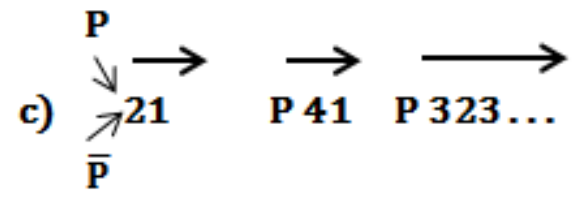

d)

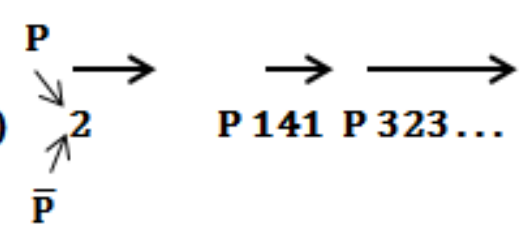

As far as auditory play signals are concerned, very little is known. Many mammals perform what has been termed a 'play pant', a rhythmic, audible expiration. However, the role of this sound, or of any other vocalization(s) in the initiaton and/or maintenance of play, has not been demonstrated. Wilson and Kleiman (1974) offer an interesting observation on the play of the rodents they observed (see above). In Octodon degus, whose play appears to be less dependent on olfactory exchange than either Octodontomys gliroides or Pediolagus salinicola, a soft purring vocalization ('gurgling') is heard during play, while a similar vocalization has not been recorded for 0 . gliroides or $P$. salinicola.

Finally, tactile stimuli may be important in the play of various mammals, but even less systematic research has been conducted concerning this mode of communication and its relationship to play.

In conclusion, although play signals have been described for a wide range of mammals, nothing definite beyond a temporal correlation between the performance of one of these signals and the subsequent occurrence of play was been reported. Correlations are insufficient data for stating that play signals function metacomrnunicatively (as defined above). As Moynihan (1973:22) has written concerning other areas of ethology, what is lacking in many studies is "...attention to some of the details of the ongoing 
processes...how and why they actually work in fact and in nature, the mechanisms by which the final results are achieved."

\section{FUNCTIONAL PLAY SIGNALS IN THE COYOTE (Canis latrans)}

To date it has been accepted that metacomrnunicative signals do exist and are functional in altering the significance of subsequent behaviors, despite the absence of quantitative data to support this assumption. Since existing data are insufficient, a series of comparative developmental studies of social play were undertaken on infant coyotes (C. latrans), wolves (C. lupus), and beagles (C. familiairis), in order both to study and compare sequences of behavior during social play and agonistic interactions (see Note 4) and to determine whether or not play signals functioned metacommunicatively (Bekoff, 1974, in preparation).

During early life, there is a large difference in the ontogeny of social behavior in these canids, the coyotes being significantly more aggressive and less playful than either the wolves or the beagles (Bekoff, 1974). My findings concerning the differential development of social play in these three species may be summarized as follows: (1) The beagles were significantly more successful in initiating play than either the wolves or the coyotes, and the wolves were significantly more successful than the coyotes. However, when the coyotes did engage in social play, $90 \%$ of all bouts had been preceded by a play signal (see Bekoff, 1974, for a description of these signals and for an elaboration on these summarized findings). (2) In the coyotes, there was a tendency to use the most successful play signals most frequently (or, alternatively, the most frequently used actions were the most successful). This trend was not observed in the wolves or beagles. Since the coyote shows very high levels of aggression early in life, there is a prevailing 'aggressive atmosphere'. Furthermore, during social play, the actions used are those otherwise observed during true aggression (no 'sexual play' was observed in the coyotes). For the coyotes, then it would be important both to communicate play intention and to have this intention be perceived and shared by the recipient. In both pairs of coyotes, the subordinate animal was more solicitous and successful than its dominant sibling, and also performed more play signals later on in the play bouts. Another observation that supports the idea that coyote play signals may be functional concerns the behavior of the dominant female of one of the pairs, and the response to her play invitations by her subordinate brother. When she attempted to initiate chase play by running towards him, she was successful on 1 time out of 40, her lone success occurring on the only occasion in which she had signalled previously with a play signal.

The above findings suggest that coyote play signals are functional in Initiating and maintaining play, and imply, but do not prove, that they serve a metacommunicative role.

In order to gain more insight into the communication of play, a detailed sequential analysis of 92 interactions was conducted for one pair of coyotes. This pair of animals was chosen because dominance relations were well established during the course of observation, and it was possible therefore to analyze aggressive as well as playful interactions. (The second pair of coyotes, the beagles, and the wolves did not engage in a sufficient number of agonistic interactions during this time period to perform a meaningful quantitative analysis). The basic question asked was: Does the performance of a play signal alter the significance of subsequent aggressive signals? In particular, does a 'play signal' alter the significance of subsequent offensive threat in such a way that the response of the recipient of the threat is different from the response that typically follows threat? The most usual response in infant coyotes to offensive threat is the immediate assumption of a submissive posture (rolling over on the side or back), and on some occasions, active avoidance of the threatening animal (running away with the tail tucked and ears pressed back against the head). In probabilistic terms, then, I am inquiring as to whether or not the 
probability of observing submission in response to threat is different (lower?) if the threat had been preceded by a play signal, than if it were not; the data were analyzed accordingly.

In order to answer the question presented above, the following three situations were considered:

1) a play signal immediately preceding a threat;

2) a play signal occurring as the first action of the interaction but not immediately preceding a threat; these are referred to as solicited interactions; and

3) no play signal observed before the threat.

A summary of the data are presented in Table 1 . Solicitation of play leads to immediate threat on only 2 out of 19 (11\%) occasions, and on both occasions, the threat was responded to with playful chase by the recipient and subsequent reciprocal play consisting of chase and mutual biting. In neither case was there any assertion of dominance or submission. In solicited interactions, threat resulted in further play soliciting $5 / 10(50 \%)$ times (3 times by the recipient of the threat) and submission 6/22 (17\%) times (Table 1), all by the recipient of the threat. In addition to the chi-square analysis performed on Table 1, a chi-square analysis was performed on the entire $70 \times 70$ contingency table. ${ }^{6}$ This latter analysis indicated no significant deviation for the observed frequency of submission (6) following threat from the expected value of $5(p>$. 05).

The results for those sequences in which no play signals were observed before the threat are quite different from those for situations (1) or (2). There were no instances of threat leading to further play soliciting. More importantly, threat resulted in immediate submission by the recipient $68 / 119(57 \%)$ times (Table 1; an analysis of the entire $70 \times 70$ table yielded an expected frequency of $48, X^{2}=8.33$, df $=1$, $\mathrm{p}<.01)$.

Table 1. The frequency with which threat (T) resulted in either submission (TS) or no submission (TS) in two situations.

\begin{tabular}{|lccc|}
\hline & $\mathbf{P S} / \mathbf{T}^{\mathbf{a}}$ & $\overline{\mathbf{P S}} / \mathbf{T}^{\mathbf{b}}$ & Row Total \\
\hline $\mathrm{TS}^{\mathrm{c}}$ & ${ }^{6}(12)^{\mathbf{e}}$ & ${ }^{68}(62)$ & 74 \\
$\mathrm{TS}^{\mathrm{d}}$ & ${ }^{16}(10)$ & ${ }^{51}(57)$ & 67 \\
Column Total & 22 & 119 & 141 \\
\hline \multicolumn{2}{c}{$\left(\mathrm{X}^{2}=7.81, \mathrm{df}=1, \mathrm{p}<.01\right)$} \\
\hline
\end{tabular}

These data demonstrate clearly that the response of a threatened animal differs according to whether or not a play signal occurred earlier in the interaction. If a play signal did occur, submission follows threat significantly less frequently than if a play signal did not occur.

${ }^{a}$ bouts with a play signal preceding threat

${ }^{\mathrm{b}}$ bouts in which there were no preceding play signals

${ }^{\mathrm{c}}$ threat followed by submission

${ }^{d}$ threat followed by some behavior other than submission

e expected values

\section{CONCLUSION}

The above data indicate that play signals do function metacommunicatively for the animals studied. The response to threat after a play signal had either immediately preceded the threat, or occurred in the beginning of an interaction is different from the response to threat in the absence of any preceding play signal. That is the probability of observing submission after a threat had been preceded by a play signal 
was lower than if the threat had not been preceded by such a signal. Therefore, it may be stated that the play signal somehow altered the 'meaning' or significance of a subsequent aggressive signal, establishing a 'play mood' (see Fig. 3 in Bekoff, 1976) and functioning as a metacommunicative signal.

In conclusion, more careful, quantitative descriptions of social play and its initiation and maintenance are needed. The ways in which play signals of various modalities are incorporated into play bouts must also be detailed. In answer to the question posed in the title of this paper, "Are play signals functional?", a cautious yes appears to be the most appropriate response.

\section{NOTES}

* I would like to thank Ernst Reese, Jeff Mitton, and Robert Fagen for their comments on an earlier version of this paper. I am grateful to Robert Fagen for his help with the analysis of these (and other) data.

${ }^{1}$ Armstrong (1973:69, 237-39) provides an interesting discussion of the relationship between bird song and play.

${ }^{2}$ At this point, with so few data available, it would be premature to speculate whether or not there has to be metacommunication for animals to be able to engage in social play.

${ }^{3}$ See Reynolds (1972), Bekoff (1972), and Vol. 14(1) of the American Zoologist (1974).

${ }^{4}$ It should also be pointed out that there have been only a few studies in which social play itself has been characterized for the species under consideration (Bekoff, 1976). Statements to the effect that the sequential patterning of actions during play differs from, and is more random than, sequences observed during non-play (e.g., Loizos, 1966, 1967), may or may not be true, since sufficient comparative analyses have not yet been performed. One universal characteristic of social play appears to be that the behaviors associated with play, and those that are 'borrowed' from other contexts are performed in a loose, bouncy manner.

We are also in the dark as concerns the function of play, and whether or not "...an animal practices in play the skills and activities he needs when grown..." (Jay, 1968:501) remains a debatable issue. Schaller (1972:165) has correctly written that it is by no means clear that information derived from play actually benefits the animal. Symons (1974) has demonstrated that during aggressive play, rhesus monkeys do not learn, refine, or practice agonistic signals. By assuming that play behavior results in immediate costs (such as expenditure of time and energy, and possible exposure to physical risk) and delayed benefits (physical training, incidental or other forms of learning, or skill development), Fagen (1974) demonstrated, using mathematical models, that play behavior can evolve under natural selection, although it will do so only under particular conditions.

${ }^{5}$ However, Wilson's (1974) analysis of play by juvenile common seals off the coast of Ireland indicates that in this species (Phoca vitulina vitulina) and in this locale, "...dyadic play...seems to be composed of patterns not found in other functional contexts"(55).

${ }^{6} 70 \times 70$ complete contingency tables were generated, including data for both animals of all the pairs of canids that were observed. From these tables it was possible to do a detailed comparative analysis of transitional probabilities (between acts) and consequently gain greater insight into behavioral sequences performed both during play and aggression (Bekoff, in preparation; Bekoff and Fagen, unpublished data). This, and other programs concerned with sequential analyses, are available from the author. 


\section{REFERENCES}

Altmann, S.A.

1962 "Social Behavior of Anthropoid Apes: Analysis of Recent Concepts", Roots of Behavior, ed. by E.L. Bliss (New York: Hafner), 277-85.

1967 "The Structure of Primate Social Communication", Communication Among Primates, ed. by S.A. Altmarm (Chicago: University of Chicago Press), 325-62.

Armstrong, E.A.

1973 A Study of Bird Song (New York: Dover).

Bateson, G.

1955 "A Theory of Play and Fantasy", Psychiatric Research Reports A 2, 39-51.

Bekoff, M.

1972 "The Development of Social Interaction, Play, and Metacommunication in Mammals: An Ethological Perspective", Quarterly Review of Biology 47, 412-34.

1974 "Social Play and Play-Soliciting by Infant Canids", American Zoologist 14, 323-40

1976 "Social Play and Social Development", Perspectives in Ethology (Vol. 2), ed. by P.P.G. Bateson and P.H. Klopfer (New York: Plenum).

in preparation "A Sequence Analysis of Social Interaction in Infant Canids: Social Play and Aggression".

Carpenter, C.R.

1974 "Aggressive Behavioral Systems", Primate Aggression, Territoriality, and Xenophobia, ed. by R.L. Holloway (New York: Academic Press), 459-96.

Chevalier-Skolnikoff, S.

1974 "The Ontogeny of Communication in the Stumptail Macaque (Macaca arctoides)"; Contributions to Primatology, No. 2.

Fagen, $\mathrm{R}$.

1974 "Theoretical Bases for the Evolution of Play in Animals", Ph.D. Dissertation, Harvard University, Cambridge, Massachusetts.

Fox, M.W.

1970 "A Comparative Study of the Development of Facial Expression in Canids: Wolf, Coyote, and Foxes", Behaviour 36, 49-73.

Hinde, R.A. (ed.)

1972 Non-Verbal Communication (New York: Cambridge University Press). 
van Hooff, J.A.R.A.M.

1967 "The Facial Displays of the Catarrhine Monkeys and Apes", Primate Ethology, ed. by D. Morris (Chicago: Aldine), 9-88.

Jay, P.

1968 "Primate Field Studies and Human Evolution", Primates, ed. by P. Jay (New York: Holt), 487503.

Laizos, C.

1966 "Play in Mammals", Symposium of the Zoological Society of London 18, 1-9.

1967 "Play Behavior in Higher Primates: A Review", Primate Ethology, ed. By D. Morris (Chicago: Aldine), 226-82.

McBride, G.

1968 "On the Evolution of Human Languages", Social Science Information 7, 81-5.

Moynihan, M.

1973 "The Evolution of Behavior and the Role of Behavior in Evolution", Breviora No. 415.

Reynolds, P.C.

1972 "Play and Human Evolution", Paper read at the Meetings of the American Association for the Advancement of Science, Washington, D.C.

Sade, D.

1973 "An ethogram for rhesus monkeys, I. Antithetical contrasts in posture and movement", American Journal of Physical Anthropology 38, 537-42.

Schaller, G.B.

1972 The Serengeti Lion (Chicago: University of Chicago Press).

Scheflen, A.E.

1974 How Behavior Means (New York: Anchor).

Simonds, P.E.

1974 The Social Primates (New York: Harper and Row).

Symons, D.

1974 "Aggressive Play and Communication in Rhesus Monkeys (Macaca mulatto)", American Zoologist 14, 317-22. 
Tembrock, G.

1957 "Spielverhalten beim Rotfuchs", Zoologisch Beitriige (Berlin) 3, 423-96.

Thorpe, W.H.

1972 "The Comparison of Vocal Communication in Animals and Man", Non-Verbal Communication, ed. by R.A. Hinde (New York: Cambridge University Press), 27-47.

West, M.

1974 "Social Play in the Domestic Cat", American Zoologist 14,427-36.

Wilson, S.

1973 "The Development of Social Behavior in the Vole (Microtus agrestis)", Zoological Journal of the Linnean Society 52, 45-62.

1974 "Juvenile Play of the Common Seal, Phoca vitulina vitulina, with Comparative Notes on the Grey Seal, Halichoerus grypus", Behaviour 48, 37-60.

Wilson S. and D.G. Kleiman

1974 "Eliciting Play: A Comparative Study", American Zoologist 14,341-70. 